Miroslav Pavelek - Pavol Spanik - Michal Frivaldsky*

\title{
VOLTAGE STRESS REDUCTION ON COMPENSATION CAPACITORS OF WIRELESS CHARGING SVSTEMS FOR TRANSPORT AND INDUSTRIAL INFRASTRUCTURE
}

The paper deals with a proposal for circuit configuration of series-series (SS) compensated wireless power transfer (WPT) system with reduced voltage stresses on compensation capacitors. Nowadays, a huge effort is given for the development of reliable, efficient and robust wireless charging systems and therefore the circuit configuration and component selection are crucial to meet suitable operational characteristics. For this purpose, the current trends in WPT systems are outlined in the first section. Next, the analysis of frequently utilized WPT system configuration is provided and the most critical issues related to practical utilization are discussed. Consequently, the proposal of how to eliminate negative aspects is given. All theoretical statements are supported by mathematical apparatus of the proposed system and consequently by the simulation analysis.

Keywords: wireless power transfer, resonance, capacitor, voltage stress

\section{Introduction}

Development of power electronics in last decades enables the massive rise of consumer and industrial electronic devices. Together with this rise, the autonomy of electronics becomes also very important. This means that self-operation without the necessity of component supplement with grid electricity acts as a major feature how to become independent. The way of such realization is the utilization of energy storage systems like accumulators or super capacitors. Nowadays, almost in every application, the usage of long-durability accumulators is necessarily inevitable (cell-phones, laptops, lighting, biomedical, etc.) [1-3]. Current trends in energy recharge are still mostly based on the wired chargers, but the wireless power transfer (WPT) is increasingly getting into the forefront of technology when talking about advanced charging systems [4-5].

IPT (inductive power transfer), as well as CPT (capacitive power transfer), are the most pervasive methods used for wireless charging [6-8]. IPT is most common and is applicable to many power levels and gap distances. CPT is only applicable for power transfer with inherently small distances. There are also various requirements for main circuit configuration e.g. configuration of resonant compensation network etc. This affects the system transfer characteristics and electrical behavior of key circuit components [9-10]. It is now well known that series-series compensation is the most suitable for the wide spectrum of practical applications. However, one disadvantage is typical and must be carefully considered, it is voltage stress of compensation capacitors. This voltage stress is several times higher (it depends on the operational quality factor) against the supply voltage. For that reason, the structural design of optimal compensation capacitor is quite a difficult issue. A possible way is to use either a special high-voltage capacitor which is very expensive or series- parallel connection of several capacitors even with high-voltage sustainability. This can be a limiting factor for many applications especially when the cost comes into account.

This paper proposes a solution for SS compensation system with reduced voltage stress of compensation capacitors. Given recommendations are initially expressed by the mathematical apparatus, while dependencies of critical variables (compensation capacitor voltage) are identified. The principal operation of system proposal is then verified by the simulation model with high level of validity.

\section{Series-series resonant compensated WPT system}

The equivalent circuit of the WPT system with resonant compensation configured in series-series topology is shown in Figure 1. The compensation capacitors $C_{1}$ and $C_{2}$ are connected to the primary and the secondary coil in series. Based on this, the resonant tank acts as a band-pass filter with relatively good selectivity.

It is generally known that to maximize the output power, both parasitic resistances $\left(R_{1}\right.$ and $\left.R_{2}\right)$ must be minimized as much as possible [11]. To evaluate the behavior of the system, the basic circuit analysis was performed. The simulation parameters are taken from two identical experimental prototypes of coupling coils. Their values are therefore the same on the primary and the secondary side. The principal design procedure has been already described in [12-13], therefore it won't be discussed here more in detail. The self-inductances are equal to $L_{1}=L_{2}=127.4 \mu \mathrm{H}$, parasitic resistances are $R_{1}=R_{2}=0.447 \Omega$ and the load is $R_{L}=30 \Omega$. The operational frequency range is set according to the main resonant frequency $\left(f_{\text {range }}=290 \mathrm{kHz} \div 340 \mathrm{kHz}\right)$. Both compensation capacitors have also the same capacity $C_{1}=C_{2}=2 \mathrm{nF}$.

\footnotetext{
* Miroslav Pavelek, Pavol Spanik, Michal Frivaldsky

Department of Mechatronics and Electronics, Faculty of Electrical Engineering and Information Technology, University of Zilina, Slovakia

E-mail: michal.frivaldsky@fel.uniza.sk
} 


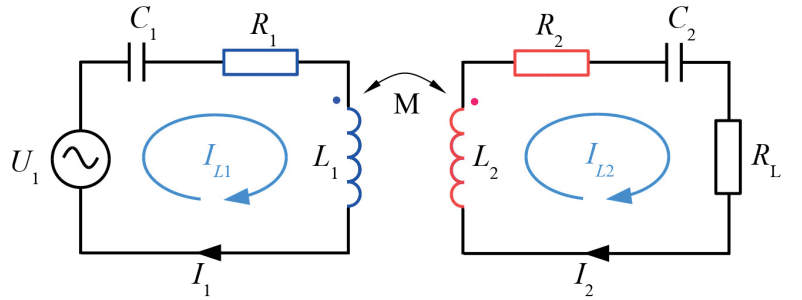

Figure 1 The equivalent circuit of WPT with series-series resonant compensation

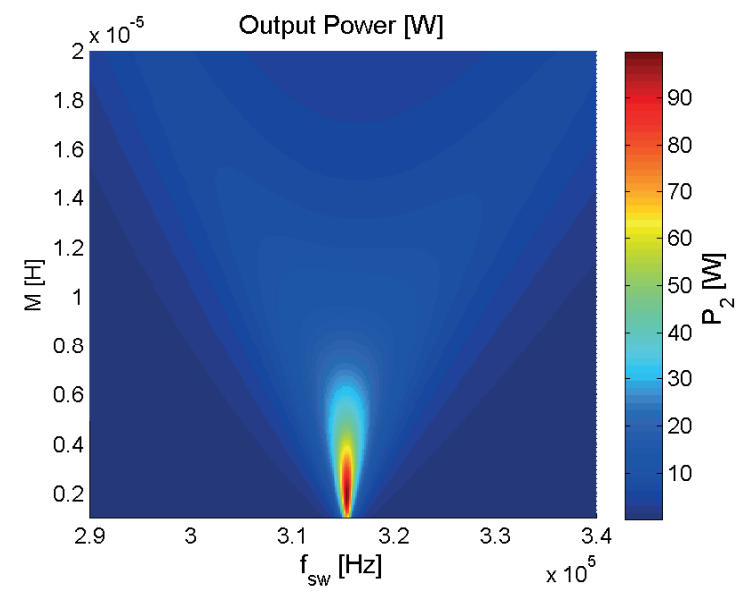

Figure 2 Power delivered to the load in case of resonant coupling with series-series compensation

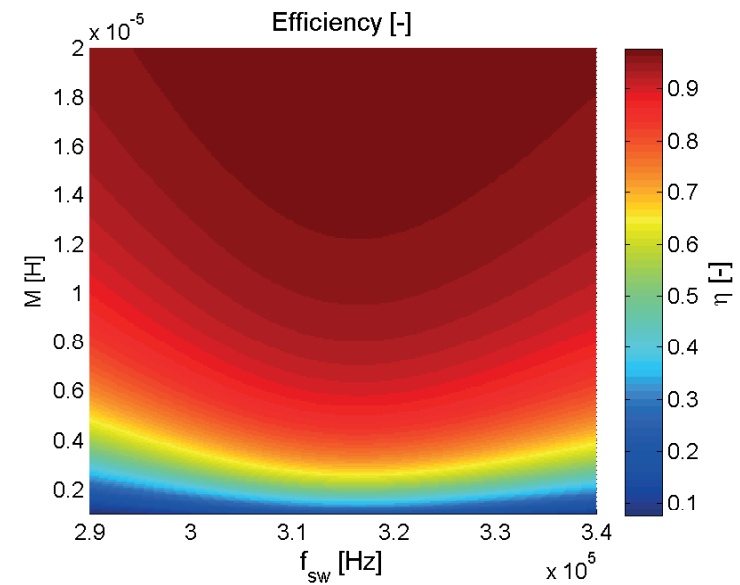

Figure 3 Transmitting efficiency in case of resonant coupling with seriesseries compensation

In the simulation, the minimal mutual inductance $M_{\min }=1 \mu \mathrm{H}$ corresponds to the transmitting distance $55 \mathrm{~cm}$ while its maximal value $M_{\max }=20 \mu \mathrm{H}$ represents the distance $10 \mathrm{~cm}$. Simulated distance range was chosen according to requirements for battery charging of electrical vehicles, i.e. for the transportation systems.

Power delivered to the load and the resulting efficiency is seen in Figures 2 and 3. The figures are constructed (using MATLAB) as follows. The operating (switching) frequency is given in $\mathrm{x}$-axis while the y-axis represents the various mutual inductance. It is

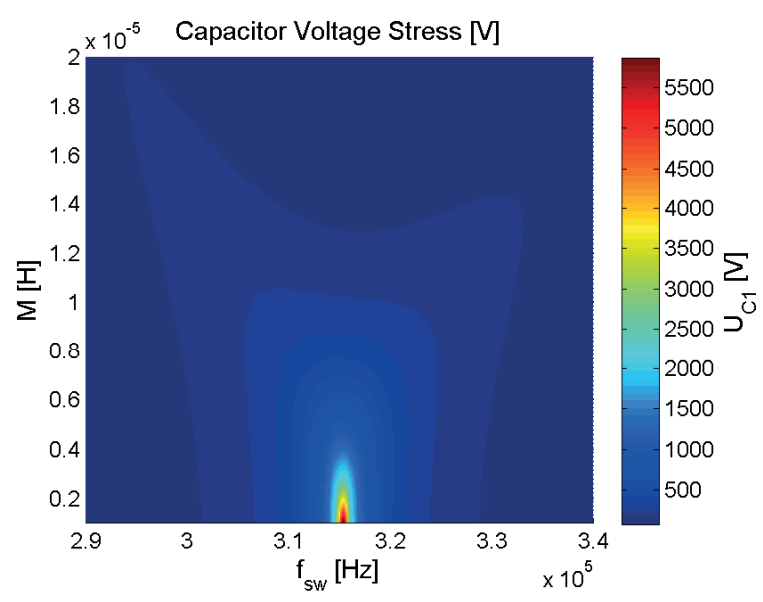

Figure 4 The voltage on the compensation capacitor $C_{1}$ for standard SS WPT system

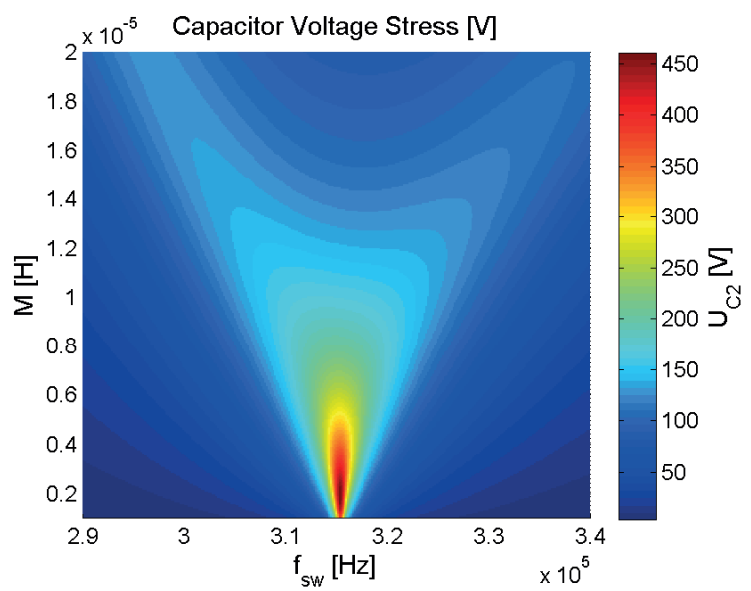

Figure 5 The voltage on the compensation capacitor $C_{2}$ for standard SS WPT system

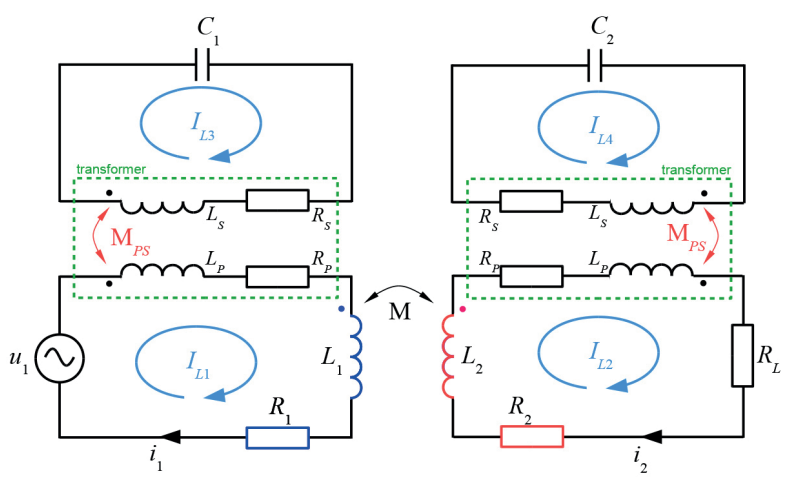

Figure 6 The equivalent circuit of WPT with series-series resonant compensation and reduced voltage stress on compensation capacitors

therefore, a 3D interpretation of particular quantities expressed as a function of two variables.

Based on this, it is clear that the operation of the system can be ensured under various conditions. It depends on the target application and actual system conditions whether high power and mid-range efficiency or very high efficiency and mid-range power are required. Mentioned parameters are strictly dependent on the optimal load (value of $\mathrm{R}_{\mathrm{L}}$ ) of the WPT system, which is for individual cases different and must be therefore exactly identified [13]. 


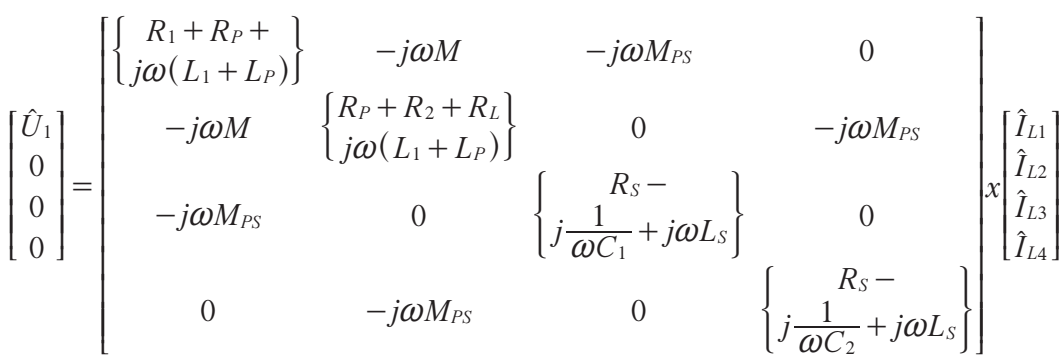

$$
\begin{aligned}
& f_{o}=\frac{1}{2 \pi \sqrt{L_{S} C_{1,2}}}, L_{S}=\frac{L_{P}}{n^{2}} \\
& U_{C 1}=\left|\frac{\left[R_{2}+R_{L}+j\left(\omega L_{2}-\frac{1}{\omega C_{2}}\right)\right] \hat{U}_{1}}{\left[R_{1}+j\left(\omega L_{1}-\frac{1}{\omega C_{1}}\right)\right] \cdot\left[R_{2}+R_{L}+j\left(\omega L_{2}-\frac{1}{\omega C_{2}}\right)\right]+(\omega M)^{2}}\right| \cdot \frac{1}{n \omega C_{1}}, \\
& U_{C 2}=\left|\frac{j \hat{U}_{1} \omega M}{\left\lceil R_{1}+j\left(\omega L_{1}-\frac{1}{\omega C_{1}}\right)\right] \cdot\left[R_{2}+R_{L}+j\left(\omega L_{2}-\frac{1}{\omega C_{2}}\right)\right]+(\omega M)^{2}}\right| \cdot \frac{1}{n \omega C_{2}} \text {. }
\end{aligned}
$$

Figures 4 and 5 show the voltage stress of particular compensation capacitors $\left(\mathrm{C}_{1}, \mathrm{C}_{2}\right)$. It can be seen that even for the very low value of supply voltage (in this case $30 \mathrm{~V}$ ), the peak voltage at each component is several times higher than the supply voltage. The situation is most critical when the system operates at a resonant frequency, or at its close range and also when the low value of mutual inductance is formed by high operational distance. Carefully designed capacitor structure and its physical configuration is therefore the most difficult issue [14-17].

\section{WPT system with reduced voltage stresses on compensation capacitors}

As previously mentioned, most limiting factor for practical use of S-S compensated WPT system is high voltage stress on compensation capacitors. A possible way how to solve this problem is to use either an appropriate series-parallel connection of discrete capacitors with the required value of capacitance and voltage sustain level or special high voltage capacitors which are usually very expensive [18-19]. Another possibility is to lower the coils' inductance which reduces the overall stress voltage across the resonant tank. This solution may debase the value of the coil's quality factor and consequently shorten the usable distance range.

Figure 6 shows proposed resourceful circuit modification which significantly reduces voltage stress on compensation capacitors. The solution uses ordinary components and is therefore cheaper. The system may be sufficiently described by the loop current method as seen in Equation (1). It is considered that the variables marked with $\wedge$ are considered as peak values.

Both compensation capacitors are replaced with a combination of capacitors and transformers whose secondary circuits are tuned at the resonant frequency given in Equation (2). The system behavior is quite sensitive to the selection of primary inductance $L p$ and transformer voltage ratio $n$. Its leakage inductance must be minimized as much as possible.
With the simplification of (1) in the way the transformers are considered as ideal with voltage ratio $n$, we may derive a general equation for voltages on compensating capacitors (3) in dependency on the frequency.

\section{Frequency analysis of proposed system}

In order to validate the proposed circuit solution, the system analyses have been done using Equation (1). The output power, transmitting efficiency and voltage stress on $C_{1}$ and $C_{2}$ corresponds to a voltage ratio of compensation transformer $n=2$.

The simulation parameters are same as used in the previous model and thus the self-inductance equals to $L_{1}=L_{2}=127.4 \mu \mathrm{H}$, parasitic resistance is $R_{1}=R_{2}=0.6 \Omega$ and the load is $R_{L}=30 \Omega$. The analyzed frequency range $f_{\text {range }}=310 \mathrm{kHz} \div 320 \mathrm{kHz}$ is not as wide as found in the previous case. Primary inductance of both compensation transformer on the transmitting and receiving side is set to $L_{P}=10 \mu \mathrm{H}$. Secondary inductance is calculated from Equation (3), $L_{S}=2.5 \mu \mathrm{H}$. The parasitic resistances on the secondary side of the compensation transformer plays an important role and was therefore minimized $R_{S}=0.025 \mathrm{~m} \Omega$. Primary resistances are considered within resistances $R_{1}$ and $R_{2}$. Finally, compensation capacitors $C_{1}$ and $C_{2}$ were determined from Equation (4) and $C_{1}=C_{2}=110 \mathrm{nH}$. Minimal mutual inductance is $M_{\min }=1 \mu \mathrm{H}$ while its maximal value $M_{\max }=20 \mu \mathrm{H}$.

Simulation results for the low value of transformer ratio are shown on Figures 7-10. As mentioned before, frequency operational range became narrower which is obvious from all discussed results.

Principal aim for our modified S-S system is to reduce voltage stress on compensation capacitors. Compared to the standard solution the voltage (Figures 4 and 5) on the compensation capacitors is due to compensation transformer reduced up to 3-times (Figures 9 and 10) for individual operating regions.

On the contrary, it can be seen (Figure 8) that even low value of parasitic resistances measured on the secondary side 


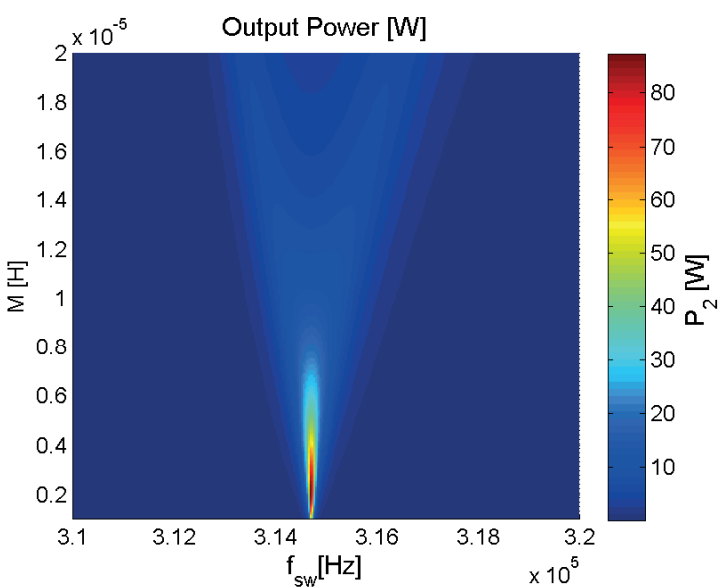

Figure 7 Power delivered to the load $(n=2)$

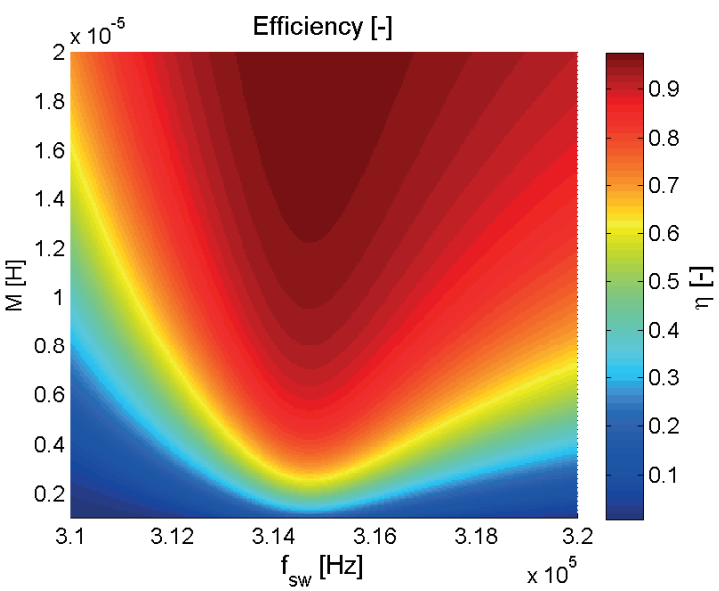

Figure 8 Transmitting efficiency $(n=2)$

of compensation transformers greatly influences transmitting efficiency. Similarly, to other variables, the frequency range became narrower whereby area with high efficiency (above 90\%) became smaller as compared to Figure 3.

The previously described analysis of the proposed system behavior was further verified by the circuit simulation in timedomain, whose results are shown within the next chapter.

\section{Simulation analysis of proposed system}

The proposed circuit solution was verified also with the use of transient simulation (Figures 14 and 15) implemented as PSpice model. Figure 11 shows the full circuit configuration which is suitable for charging or supplying various devices in this case for demonstration lap-tops, tablets or LCD displays, but it is not explicitly excluded that the proposed methodology is suited just for this kind of application. All key circuit components are set according to the previous model described in section IV. i.e.:
- $\mathrm{U}_{1}=30 \mathrm{~V}$
- $\mathrm{L}_{1}=\mathrm{L}_{2}=127.4 \mu \mathrm{H}$
- $\mathrm{L}_{\mathrm{s}}=2.5 \mu \mathrm{H}$.
- $\mathrm{R}_{1}=\mathrm{R}_{2}=0.6 \Omega$
- $\mathrm{R}_{\mathrm{L}}=30 \Omega$.
- $\mathrm{f}_{\text {range }}=310 \mathrm{kHz} \div 320 \mathrm{kHz}$

- $\mathrm{L}_{\mathrm{p}}=10 \mu \mathrm{H}$.

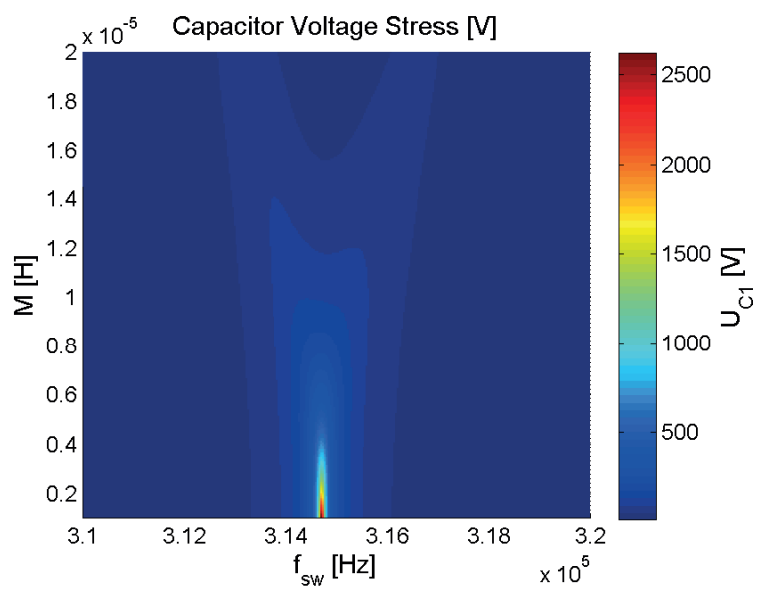

Figure 9 The voltage on the transformed $(n=2)$ compensation capacitor $C_{1}$

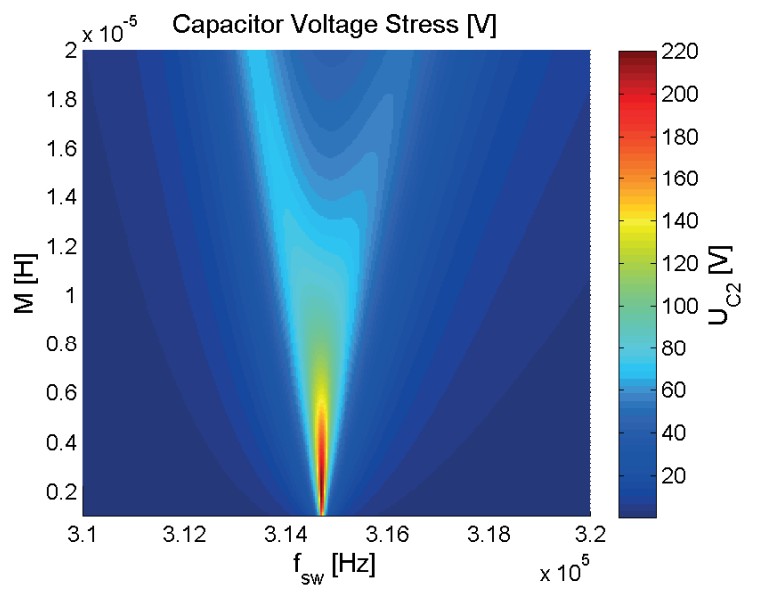

Figure 10 The voltage on the transformed $(n=2)$ compensation capacitor $C$

Only two mutual positions (mid-distance and maximal distance) of transmitting and receiving coils are simulated. The minimal considered distance is 25 centimeters which corresponds to the coupling coefficient between respective coils $k=0.09$ ( $\mathrm{M}=11$ $\mu \mathrm{H})$. The maximal distance investigated is $55 \mathrm{~cm}$ which changes the coupling coefficient in $k=0.04(\mathrm{M}=5 \mu \mathrm{H})$.

Investigation of the transfer properties of standard SS resonant WPT system and WPT system with compensation transformer were realized within frequency sweep analyses. It is obvious that for selected mutual positions the system reaches the maximal available power and efficiency precisely at the resonant point. This operating state is optimal for the transmitting power and the efficiency but in case of standard circuit configuration (Figure 1) it is highly stressful for the resonant capacitors (Figure 12), where maximum of the voltage stress is achieved for the resonant point of operation [10]. Similar situation but for the system with compensation transformer is shown in Figure 13. The maximal power delivery and efficiency are achieved again close to the resonant point, and capacitor voltage stress is at its peak, but compared to results from Figure 12, it is half of its value. It must be mentioned here, that the resonant points are different when standard and optimized WPT systems are considered. This is caused by the slightly different capacitor value when compensation transformer is considered, while its value is 

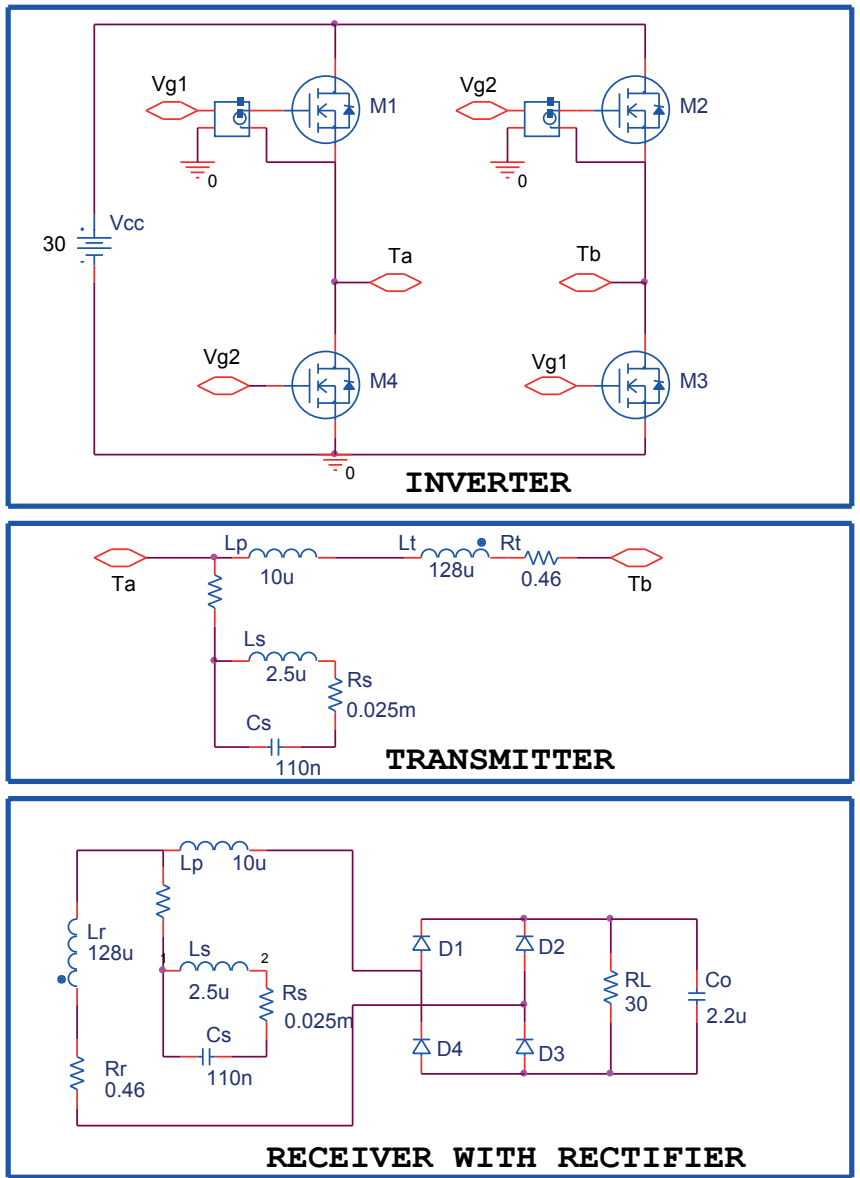

Figure 11 A simulation model of the proposed WPT system voltage on the transformed $(n=2)$ compensation capacitor $\mathrm{Cl}$

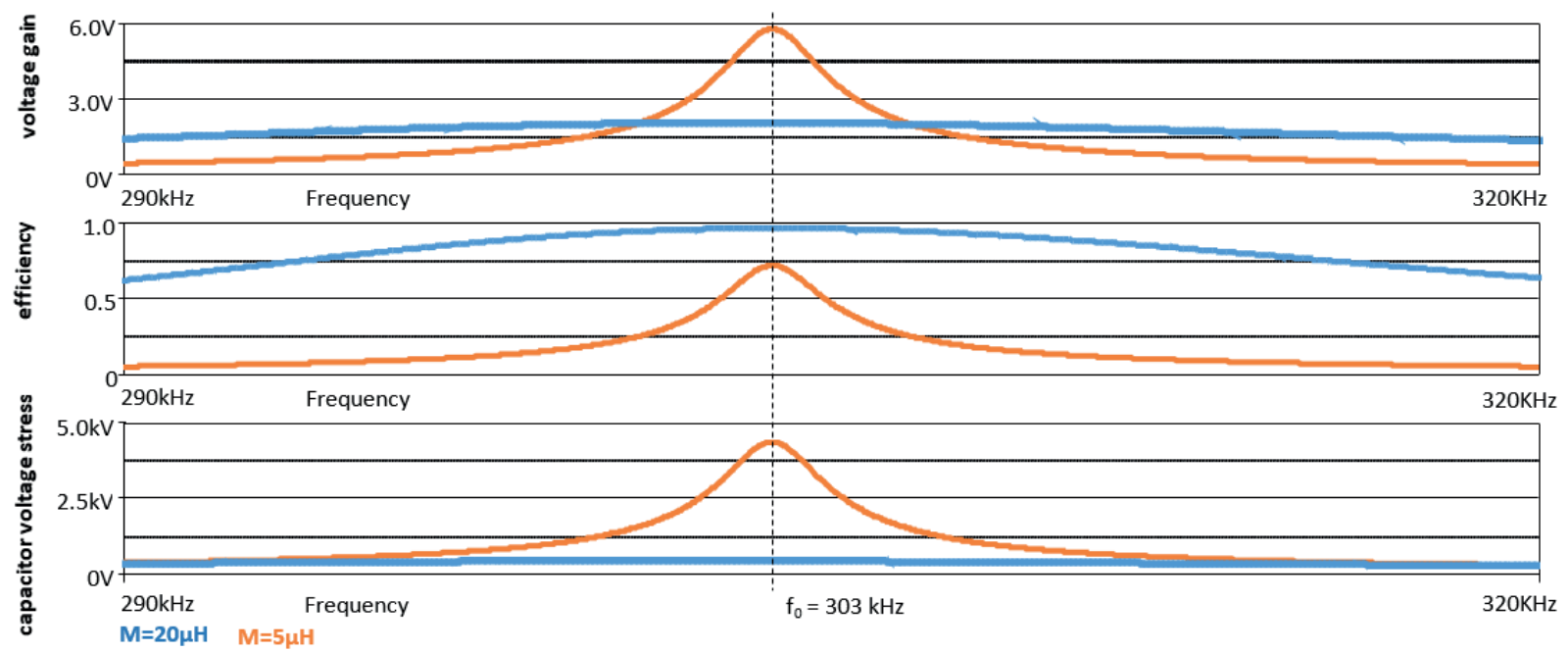

Figure 12 Transfer characteristic for standard SS resonant compensated WPT system (resonant point $=303 \mathrm{kHz}$ )

dependent on the integer value of the number of compensation transformer turns.

On the other hand, the achievable power transfer was decreased from $110 \mathrm{~W}$ to $55 \mathrm{~W}$ and efficiency from $80 \%$ to $65 \%$. This was expected because of the existence of parasitic components of compensation transformer (parasitic resistances of windings, leakage inductance). Those must be decreased as much as possible that will be the main topic for the future works, which will be related to optimization works on the compensation transformers as well as on the experimental verifications of the system proposal.

Consequent simulation experiments have been done within time-domain (Figures 14 and 15), while the mutual distance between the transmitting and receiving side was considered for the situation, where $\mathrm{M}=5 \mu \mathrm{H}($ distance $=55 \mathrm{~cm})$. In comparison to the proposed compensation technique the voltage stress of 


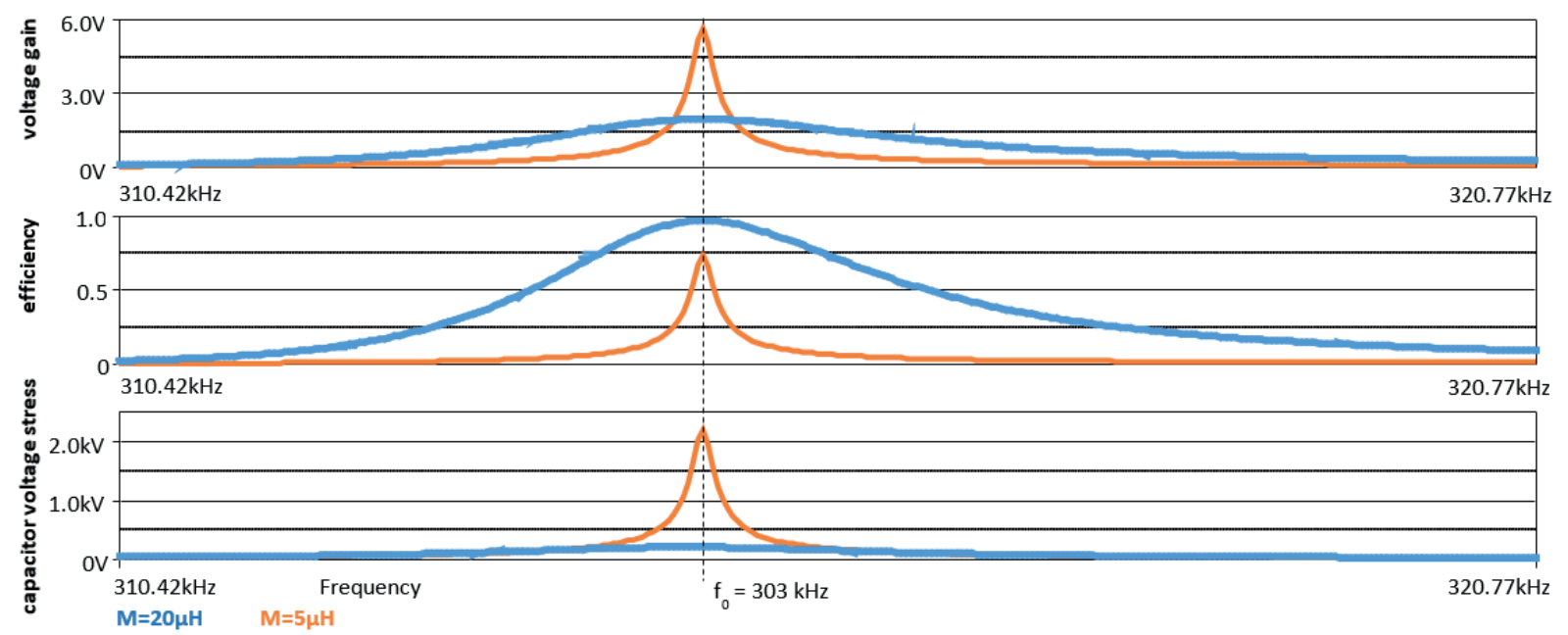

Figure 13 Transfer characteristic for WPT system with compensation transformer (resonant point $=315 \mathrm{kHz}$ )

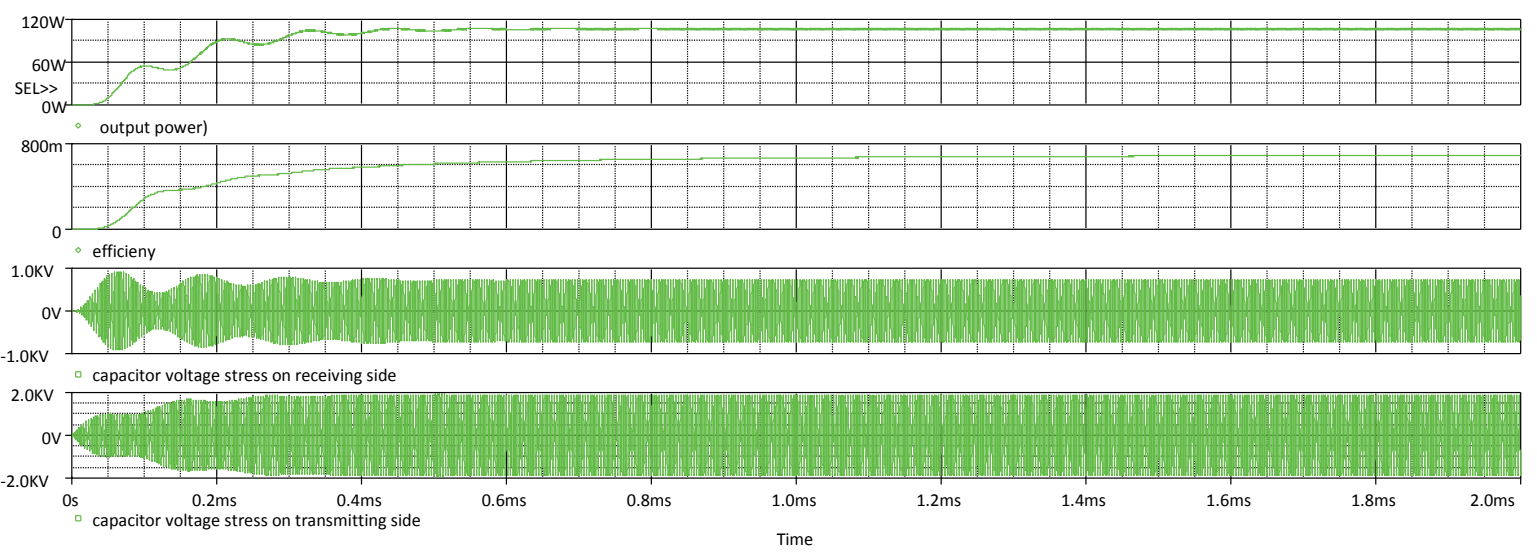

Figure 14 Simulation results of WPT system without compensation transformer (standard SS compensated system) operated at the the resonant point

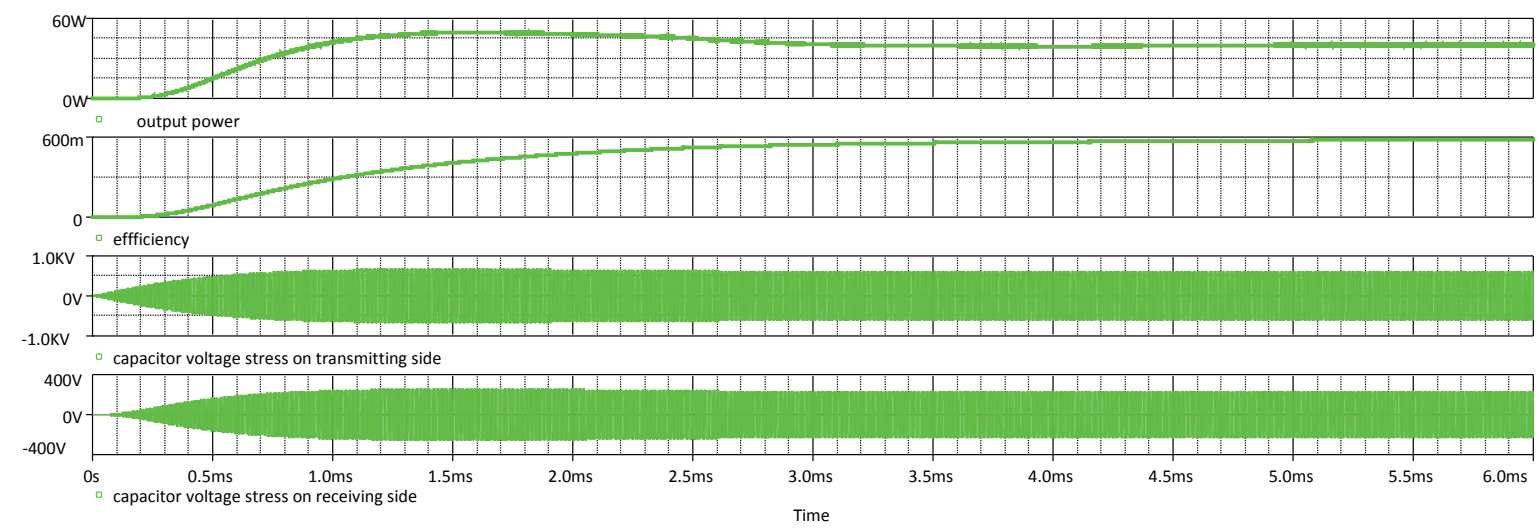

Figure 15 Simulation results of WPT system with compensation transformer operated at the resonant point

capacitors in the case of standard SS compensated WPT system is almost 4 times higher. Capacitor voltage stress for standard solution is around $2 \mathrm{kV}$ for transmitting side, while for receiving side it is around $750 \mathrm{~V}$ (Figure 14). Proposed solution is acting as follows; transmitting side has voltage stress at the level of $600 \mathrm{~V}$, while receiving side around $200 \mathrm{~V}$ (Figure 15).

\section{Conclusion}

In this paper, a new compensation technique for the resonant WPT system is presented. The simple design procedure is given, whereby the negative effect of individual circuit components is identified. The proposed solution significantly reduces the voltage stress of compensation capacitors. This is basically dependent on the design of the compensation transformer. Within proposed 
system, reduction of the voltage stress was achieved up to 3-times lower compared to standard WPT system. Simulation clearly shows all fundamental advantages and disadvantages for further practical use. It was found that the proper design of the compensation transformer will be important issue for future works, thus it has the most significant impact on the whole system behavior while thinking about system efficiency and power delivering capability. Practically all investigated variables are influenced by the values of parasitic resistances on the transformer secondary side where high circulating current occurs. In other words, the higher transformer ratio enables to reduce voltage stress markedly, but on contrary it increases circulating secondary currents. Therefore, it is necessary to find out a suitable compromise that will meet all design requirements.
Future work will be focused on the practical verification of proposed solution and on its system optimization.

\section{Acknowledgment}

The authors wish to thank to Slovak National Grant Agency VEGA for the finnacial support within project Nr. 1/0119/18 - Research of the methodology for optimization of EMC of WPT systems, and for project Nr. 1/0547/18 - Research of the possibilities for system optimization of WPT systems.

\section{References}

[1] DAI, J., LUDOIS, D. C. A survey of wireless power transfer and a critical comparison of inductive and capacitive coupling for small gap applications. IEEE Transactions on Power Electronics [online]. 2015, 30(11), p. 6017-6029. ISSN 0885-8993 eISSN 1941-0107. Available from: https://doi.org/10.1109/TPEL.2015.2415253

[2] ZOSSAK, S., STULRAJTER, M., MAKYS, P. Self-Sensing Control of Pmsm at Zero and Low Speed . Communications - Scientific Letters of the University of Zilina [online]. 2018, 20(1), p. 13-19. ISSN 1335-4205/eISSN 2585-7878. Available from: http:// komunikacie.uniza.sk/index.php/communications/article/view/39

[3] HUI, S. Y. R., ZHONG, W., LEE, C. K. A critical review of recent progress in mid-range wireless power transfer. IEEE Transactions on Power Electronics [online]. 2014, 29(9), p.4500-4511. ISSN 0885-8993/eISSN 1941-0107. Available from: https://doi.org/10.1109/ TPEL.2013.2249670

[4] KINDL, V., KAVALIR, T., PECHANEK, R. Construction Aspects of System for Wireless Low Power Transfer on Moving Parts of Electric Machinery. Communications - Scientific Letters of the University of Zilina [online]. 2015, 17(1A), p. 77-82. ISSN 1335-4205/ eISSN 2585-7878. Available from: http://komunikacie.uniza.sk/index.php/communications/article/view/416

[5] GOVIC, G. A., BOYS, J. T. Modern trends in inductive power transfer for transportation applications. IEEE Journal of Emerging and Selected Topics in Power Electronics [online]. 2013, 1(1), p.28-41. ISSN 2168-6777/eISSN 2168-6785. Available from: https:// doi.org/10.1109/JESTPE.2013.2264473

[6] ZHAI, H., PAN., H. K., MINGYU, L. A practical wireless charging system based on ultra-wideband retro-reflective beamforming. In Antennas and Propagation Society International Symposium : proceedings. 2010. ISBN 978-1-4244-4967-5, p. 1-4.

[7] KAVALIR, T., et al. Upgrading of the single point laser vibrometer into a laser scanning vibrometer . Communications - Scientific Letters of the University of Zilina [online]. 2018, 20(1), p. 61-66. ISSN 1335-4205/eISSN 2585-7878. Available from: http:// komunikacie.uniza.sk/index.php/communications/article/view/47

[8] SUKJIN, K., et al. High-efficiency PCB- and package-level wireless power transfer interconnection scheme using magnetic field resonance coupling. IEEE Transactions on Components, Packaging and Manufacturing Technology [online]. 2015, 5(7), p. 863-878. ISSN 2156-3950/eISSN 2156-3985. Available from: https://doi.org/10.1109/TCPMT.2015.2446613

[9] NOBILE, G., et al. Multi-criteria experimental comparison of batteries circuital models for automotive applications . Communications - Scientific Letters of the University of Zilina [online]. 2018, 20(1), p. 97-104. ISSN 1335-4205/eISSN 2585-7878. Available from: http://komunikacie.uniza.sk/index.php/communications/article/view/54

[10] TOMMASO, A. O. D., GENDUSO, F., MICELI, R. A small power transmission prototype for electric vehicle wireless battery charge applications. In International Conference on Renewable Energy Research and Applications : proceedings [online]. 2012, p. 1-6. Available from: https://doi.org/10.1109/ICRERA.2012.6477432

[11] MUSAVI, F., EBERLE, W. Overview of wireless power transfer technologies for electric vehicle battery charging. IEEE Transactions on Power Electronics [online]. 2014, 7(1), p. 60-66. ISSN 1755-4535/eISSN 1755-4543. Available from: https://doi.org/10.1049/ iet-pel.2013.0047

[12] Kindl, V., et al. Transfer properties of various compensation techniques for wireless power transfer system including parasitic effects. COMPEL - The International Journal for Computation and Mathematics in Electrical and Electronic Engineering [online]. 2017, 36(4), p. 1198-1219. ISSN 0332-1649. Available from: https://doi.org/10.1108/COMPEL-04-2016-0143

[13] PIRI, M., et al. Wireless (power transfer) transmission of electrical energy (electricity) intended for consumer purposes up to 50 W. Advances in Electrical and Electronic Engineering [online]. 2016, 14(1), p. 40-48. ISSN 1336-1376/eISSN 1804-3119. Available from: https://doi.org/10.15598/aeee.v14i1.1573 
[14] SZABO, L., et al. Torque smoothing of a fault tolerant segmental stator switched reluctance motor. Communications - Scientific Letters of the University of Zilina [online]. 2015, 17(1A), p. 95-101. ISSN 1335-4205/eISSN 2585-7878. Available from: http:// komunikacie.uniza.sk/index.php/communications/article/view/419

[15] KIANI, M., GHOVANLOO, M. The circuit theory behind coupled-mode magnetic resonance-based wireless power transmission. IEEE Transactions on Circuits and Systems I: Regular Papers [online]. 2012, 59(9), p. 2065-2074. ISSN 1549-8328. Available from: https://doi.org/10.1109/TCSI.2011.2180446

[16] JOLANI, F., YIQIANG, Y., CHEN, Z. Enhanced planar wireless power transfer using strongly coupled magnetic resonance. Electronics Letters [online]. 2015, 51(2), pp.173-175. ISSN 0013-5194/eISSN 1350-911X. Available from: https://doi.org/10.1049/ el.2014.4104

[17] AIELLO, G., et al. A high efficiency interleaved PFC front-end converter for EV battery charger. Communications - Scientific Letters of the University of Zilina [online]. 2018, 20(1), p. 86-91. ISSN 1335-4205/eISSN 2585-7878. Available from: http://komunikacie. uniza.sk/index.php/communications/article/view/52

[18] SOHN, Y.H., et al. General unified analyses of two-capacitor inductive power transfer systems: Equivalence of current-source SS and SP compensations. IEEE Transactions on Power Electronics [online]. 2015, 30(11), p. 6030-6045. ISSN 0885-8993/eISSN 19410107. Available from: https://doi.org/ 10.1109/TPEL.2015.2409734

[19] CHO, S.Y., et al. Series-series compensated wireless power transfer at two different resonant frequencies. In ECCE Asia Downunder (ECCE Asia) : proceedings. 2013. ISBN 978-1-4799-0482-2, p. 1052-1058. 